\title{
Does Lower Benefits Incentivize Refugee Naturalization? Evidence from a Natural Experiment
}

\author{
Frederik Juhl Jørgensen \\ Department of Political Science, Aarhus University \\ fj@ps.au.dk
}

\begin{abstract}
Does lower benefits provide an incentive for refugees to naturalize? I identify the effect of lowering refugees' benefits on their propensity to naturalize by leveraging quasi-random variation in refugees' benefit levels induced by a major reform of the Danish social assistance system. The reform sharply reduced social assistance benefits by up to 50 percent for new refugees. I estimate the effect of this decrease in a regression discontinuity design and show that refugees' propensity to naturalize jumps by about $13 \frac{1}{2}$ percentage points at the benefit cutoff. I demonstrate that this marked increase is most likely driven by increased incentives that drive refugees off welfare and into the labor market in the short-term. Moreover, I show that the positive effects on naturalization are concentrated among the most capable refugees who do not face the resource constraints that follow from low education.
\end{abstract}


After marked increases in their refugee populations, refugee integration has become a key challenge in refugee-receiving countries. One fundamental issue in the host countries is the increasing worry about abuse of their welfare systems: widespread concern that continued immigration leads to the erosion of the welfare state has prompted governments to implement policies that cut into the welfare rights of refugees. Thus, since 2002, EU27 countries have passed 126 bills that tightens the welfare levels or eligibility of immigrants and refugees. Much is at stake in this process. However, we know relatively little about the impact of these policies on integration.

Theoretically, one view argues that such policies incentivize individuals to get off welfare, find employment, and thereby promote labor market integration as a first step toward integration into the host society more broadly. This argument builds on the relatively clear-cut prediction that a reduction in public welfare transfers leads to lower reservation wages and higher jo search intensity (e.g. Mortensen 1977), which has been supported in many empirical (e.g. Bover et al. 2002; Abbring et al. 2005; Van Ours and Vodopive 2004, 2006). The contrasting view argues that these policies pose a barrier to the integration. This argument goes that welfare reductions mainly create a large underprivileged group who live on a subsistence minimum and is denied an equal share of the society's goods. In the literature, such income reductions have for example been linked to children's outcomes (e.g., Dahl and Lochner 2012; Duncan et al. 2011; Løken et al. 2012), ethnic segregation (e.g., Borjas 1998; Crowder and Krysan 2016; Sager 2012), and criminal offenses (e.g., Carr and Packham 2017; Corman et al. 2014; Foley 2011).

In this article, I contribute to the ongoing debates over benefit levels and refugee integration. I exploit that the Danish start help reform induced quasi-random variation in benefits by reducing the social assistance benefits of new refugees by up to 50 percent. While many studies examine the impacts of public income transfers, relatively little research have focused on refugees 
specifically. Moreover, most studies face the problem that it is more or less impossible to isolate the independent effects of benefit reception on integration because the reception of benefits and integration is not random. Thus, isolating the independent effects of benefits is a fairly hopeless endeavor in traditional observational studies because it is difficult to measure and control for the myriad of confounders that simultaneous affect integration and determine benefits. The few studies that exploit quasi-random variation mostly focus on short-term economic outcomes (e.g. Rosholm and Vejlin 2010; Huynh, Schultz-Nielsen, and Tranæs 2007). From a policy standpoint, the focus on short-term economic effects is concerning as it means that policy makers may not be fully aware of the consequences of their decisions when designing the policies.

I address this gap in evidence by first solving the key identification issue of omitted variable bias. I utilize that the Danish start help reform reduced social assistance benefits only for refugees who obtained residency after July 1 2002, whereas refugees who obtained residency before were eligible for regular assistance. In particular, I use this sharp cutoff in a regression discontinuity (RD) design that — just like a randomized experiment — enables me to overcome the traditional concerns of omitted variable bias. Second, I move beyond short-term economic outcome and instead focus on citizenship acquisition (as of December 31 2015) as a key indicator for integration. I draw on Danish national registers to provide direct estimates for the long-term integration effect of lower social assistance.

The findings also contribute to a well-developed literature on incentives and naturalization. Most of this literature provide only correlational evidence on the relationship between incentives and the decision to pursue naturalization or not (e.g., Aleinikoff 2001; Aleinikoff and Klusmeyer 2011; Joppke 2010; Bauböck et al. 2006; Yang 1994). An important exception is Hainmueller et al. (2018): they provide experimental evidence to show that alleviating the costs of becoming citizen has a marked positive effect on immigrants' likelihood of naturalizing. Similarly, I 
use the start help reform to show that increasing the benefits of becoming citizen (i.e. increasing costs of remaining non-citizen) has a marked positive effect on refugees' naturalization propensity.

Overall, I contribute to the literature on incentives and naturalization in four ways. First, like Hainmueller et al. (2018), I provide reliable causal evidence for the effect of incentives on citizenship acquisition. Second, whereas they demonstrate how adjusting the costs of citizenship acquisition affects naturalization rates, I show that adjusting the benefits of becoming citizen can exert a similar influence. Third, unlike Hainmueller et al. (2018) who examine a trial-based intervention on a small sample of citizenship applicants, I study a large-scale benefit reform that in practice affected all new refugees arriving in Denmark. This means that I investigate the entire target population, which contributes to our understanding of the scalability of providing incentives. Finally, the findings also expand the generalizability of their results by moving the analysis of the impacts of incentives to Denmark, which is very different from the American context.

This article yields three main results. First, reducing the benefits of refugees' increase their probability of naturalizing by about $13 \frac{1}{2}$ percentage points, which corresponds to an increase of about 70 percent relative to the sample mean. This sizable effect is robust across various robustness checks. Second, I show that this overall effect most likely reflects the incentives mechanism that propels refugees to get off welfare and find as a stepping-stone toward broader integration into the host society. Third, I demonstrate that this mechanism only functions for a certain subset of refugees who naturalize at higher rates than they would have in the absence of lower benefits: the positive effects are concentrated among the most capable refugees who do not face the resource constraints that follow from low education.

These findings have implications for theory and the design policy. For theory, the findings contributes to our understanding of how incentives influences refugees' likelihood of naturalizing. My results show that increasing the benefits of becoming citizen (or increasing the costs 
of remaining non-citizen) influences those refugees who are most resourceful and face the smallest resource constraints, whereas the results of Hainmueller et al. (2018) show that alleviating the costs of becoming citizen have the largest effects among the less resourceful who face the largest resource constraints. For policy, this is important. While the large benefit reduction incentivizes the most resourceful to naturalize, this positive effect is absent among least resourceful. For this group of refugees, the large benefit reduction might instead pose a substantial barrier to their integration into the host society because they are placed on a subsistence minimum. In a companion study, I show how the reduction in benefits negatively influences this group's long-term residential integration: they live more ethnically segregated in the long-term compared to regular assistance refugees. From a policy standpoint, this is especially concerning because it shows that lower benefits marginalize those who have little chances of integrating into the host society further and push them to the edges of the society. Taken together, these findings suggest that governments should consider designing policies that target the costs rather than the benefits of becoming citizen.

\section{Do Benefit Reductions Affect Naturalization?}

Why do some refugees pursue naturalization while others do not? From a rational choice perspective, refugees will pursue naturalization if the benefits of becoming citizen outweighs the costs. On the benefit side, refugees who naturalize gain certain legal rights and privileges that only apply to citizens of the host country (Hainmueller, Hangartner, and Pietrantuono 2017; Aleinikoff 2001; Aleinikoff and Klusmeyer 2011; Joppke 2010; Bauböck et al. 2006). In that sense, "national citizenship is the highest standard of equal treatment because refugees become citizens with all the same rights, same responsibilities, and same voice in a democracy" (Bauböck et al. 2013, 40).

Thus, only refugees who naturalize gain unrestricted access to the territory of the state with the full right to return and permanent abode. Although refugees who are permanent residents 
typically have some security and protection against expulsion, naturalization thus ultimately transforms the foreigner into a citizen (Hainmueller, Hangartner, and Pietrantuono 2017; Vink, Prokic-Breuer, and Dronkers 2013). Moreover, in countries like Denmark, where citizenship is not awarded based on place of birth, refugee children only acquire Danish citizenship if their parents naturalize. Furthermore, naturalization also gives access to employment opportunities and welfare benefits that are restricted to citizens and the increased mobility that follows from the passport of the host country (Hainmueller, Hangartner, and Pietrantuono 2017). In addition, economic studies have shown that citizenship increases refugees' employability and their income because employers take into account administrative costs of verifying the right to work when hiring foreigners (Bratsberg, Ragan, Nasir 2002; Bevelander and Devoretz 2008; Steinhardt 2012). Naturalization might also act as a signal to employers of higher levels of human capital (e.g., better language skills) and better integration of the refugee applicant and. Finally, citizenship acquisition has been shown to catalyze further economic, social, and political integration into the host society (Hainmueller Hangartner, and Ward 2019; Hainmueller, Hangartner, and Pietrantuono 2015, 2017).

On the cost side, one of the major costs is the loss of rights in the country of origin (when dual citizenship is not allowed). ${ }^{1}$ Loss of citizenship in the home country reduces or eliminates access to public benefits and restricts job opportunities and travel mobility in the country of origin (Bratsberg, Ragan, Nasir 2002; Van Hook, Brown, and Bean 2006). After September 12015 , Denmark has accepted dual citizenship, which means that refugees can now acquire a Danish citizenship without losing their right in the country of origin if the home country also accepts dual citizenship. Those who naturalize are also subject to the military draft (Bratsberg, Ragan, and Nasir 2002). Moreover, they must bear the costs incurred in the process of acquiring citizenship, including bureaucratic hassles, fees and time spent on accumulating knowledge to pass language and civic tests

\footnotetext{
${ }^{1}$ Until September 1 2015, Denmark did not accept dual citizenship.
} 
(Bratsberg, Ragan, Nasir 2002; Van Hook, Brown, and Bean 2006; Bloemraad 2006; Steinhardt 2012). In addition, they also have to pay a naturalization application fee, which in Denmark is currently 3.800 DKK ( 580 USD).

Questioning this instrumental view on naturalization, sociologists have introduced the notion of "context of reception". To account for differences across host environments, this view stipulates that the context in which refugees are received is crucial for their likelihood of naturalization (Bloemraad 2006; Fox and Bloemraad 2015; Portes and Rumbaut 2001). The idea is that tangible support provided to refugees from institutional sources shape their contexts of reception and influence how welcome they feel at arrival, how much settlement help they receive, and how much assistance they can draw on when learning the skills required for naturalization (Portes and Rumbaut 2001; Reitz 2003). Moreover, intangible attitudes toward refugees also matter by signaling whether or not refugees can feel welcome and valued in their new society (Van Hook, Brown and Bean 2006). Taken together, these factors can foster refugees' motivation to naturalize by making them feel more or less welcome and by providing more or less assistance in the naturalization process. Taken together, the instrumental and social context paradigms form the two major (complementary) theoretical views about the foundations of naturalization and the factors that shape citizenship acquisition (Van Hook, Brown, and Bean 2006).

Theoretically, the above discussions also raise the question of potential effect heterogeneity. Thus, the impact of lower benefits (i.e., the increase in incentives) may very well be contingent on refugee characteristics rather than uniform across refugees. Given their higher employability, the better educated are likely to be more capable of getting a foothold on the labor market. Moreover, self-sufficiency — for the past five years prior to citizenship acquisition—is a requirement for obtaining Danish citizenship. Taken together, this makes for the expectation that any positive incentives effect is driven by the better educated. 


\section{Is Danish Citizenship Acquisition a Good Indicator for Refugee Integration?}

Danish citizenship law is based on a jus sanguinis principle and did not follow European trends in the 2000s, where many countries extended citizenship entitlements, accepted multiple citizenship and introduced jus soli elements to facilitate naturalization. Instead, Denmark made conditions for citizenship acquisition more restrictive (Ersbøll, 2015). To be eligible for Danish citizenship, by 2015, refugees' had to satisfy eight conditions. ${ }^{2}$ First, for refugees, Denmark has a residence requirement of 8 years of uninterrupted stay. Second, it is required that the refugee holds a permanent permit. Third, refugees are excluded from naturalization if they have been sentenced to imprisonment for one year or more. Fourth, proficiency in the Danish language is required (European level B1). Fifth, refugees must be self-sufficient. This implies that a refugee cannot have received social benefits within the last year of naturalization and cannot have received social benefits for more than an aggregate period of six months period within the last five years of naturalization. Sixth, the applicant cannot be considered for citizenship if she has due debt to the state. Seventh, the applicant has to give a declaration of allegiance and loyalty to Denmark and declare that she will comply with Danish law. Finally, the applicant has to pass a citizenship test that focuses on aspects of everyday life, Danish culture, history, and political life.

In sum, the threshold for Danish citizenship acquisition is relatively high, which suggests that naturalization may be a good indicator for important integration aspects into the Danish society more broadly. In particular, the eight conditions above tap into important dimensions of the integration concept, including linguistic integration, economic integration, psychological integration, cultural integration, political integration, and social integration (Harder et al. 2018). Similarly,

\footnotetext{
${ }^{2}$ Recently, the government added a ninth condition: applicants have to participate in a ceremony to show respect for Danish values and representatives of the Danish authorities.
} 
naturalization is often used as a key measure of overall integration success in the literature (Mossaad et al. 2018). Thus, Hainmueller and Hangartner (2013) show that naturalization is an important overall indicator of successful linguistic, political, and economic integration. Moreover, Harder et al. show these dimensions of integration to be highly correlated with other dimensions including social, psychological, and navigational integration. Furthermore, citizenship acquisition has been shown to be catalyze further economic, political, and social integration (Hainmueller, Hangartner, and Pietrantuono 2015, 2017; Hainmueller Hangartner, and Ward 2019). Taken together, this means that citizenship status may be a good indicator for long-term integration into the Danish society more broadly.

\section{Research Design}

\section{The Start Help Reform}

To avoid raising questions of ethnic discrimination, the start help rules applied to all citizens who obtained residency after July 12002 and had lived abroad for more than one of the last eight years. To the contrary, refugees who obtained residency before July 12002 would generally remain eligible for regular assistance (Huynh, Schultz-Nielsen, and Tranæs 2007; Rosholm and Vejlin 2010). Residency refers to the date that the municipal council takes over the integration responsibility for the refugee, cf. the Integration Act $\S 4 .^{3}$ As an exception to the general rules, the reform capped the benefits of couples if one spouse obtained residency before the cutoff of July 1 and the other after. In particular, total household benefits were capped such that it would not exceed the amount that two refugees on start help would receive. This means that a refugee who obtained residency before the

\footnotetext{
${ }^{3}$ According to the Integration Act $\S 4$, the municipal council takes over the integration responsibility for the refugee refugee after the end of the first whole month of obtaining residence permit. If the refugee, for example, received her permit March 8, the responsibility passes to the municipal council May 1. For reunified refugees, quota refugees, and refugees who applied for asylum at Danish embassies, the municipal council takes over the integration responsibility when the refugee is registered as having arrived in the municipality or if the application is submitted in Denmark from the announcement of residence permit.
} 
reform, whose spouse obtained after, is de facto under the start help rules. As shown in Table 1, start help recipients experienced welfare reductions up to 50 percent compared to regular assistance recipients, depending on family composition. The motivation of these massive cuts was to promote labor market integration of refugees and thereby pave the way for integration more broadly (Danish Prime Minister's Office 2002). Importantly, only refugees and their reunified family members were affected systematically by the reform. Other types of immigrants, such as labor migrants, who wish to obtain residency are supposed to provide for themselves or be provided for by their spouses (Huynh, Schultz-Nielsen, and Tranæs 2007, Rosholm and Vejlin 2010). In the results section below, I therefore focus only on refugees and their families.

Table 1. Assistance Levels

\begin{tabular}{lcccc}
\hline \multicolumn{1}{c}{ Status } & Children & Regular social assistance & Start help & Percent reduction \\
\hline Single & 0 & 8,172 & 5,266 & 36 \\
Couples & 0 & 16,344 & 8,732 & 47 \\
Couples & 1 & 21,718 & 9,824 & 55 \\
Couples & $\geq 2$ & 21,718 & 10,916 & 50 \\
\hline \hline
\end{tabular}

Note: Ejrnæs (2003). Gross income in DKK.

The start help reform was part of a larger reform package that also tightened the reunification law (reunification would now only be possible if both spouse were at least 24 years old), removed the possibility of seeking asylum at Danish embassies abroad, and replaced the concept "de facto refugee" status with "protection status". These restrictions made it significantly more difficult to immigrate to Denmark both through family reunification and as a refugee (Huynh, Schultz-Nielsen, and Tranæs 2007). With typical observational data, I would risk attributing the effects of these policy changes to the effect of the start help reform. However, the start help reform referred to the date of residency whereas the other policies referred to the asylum application date (Huynh, Schultz-Nielsen, and Tranæs 2007). This means that refugees were affected equally, across the start help cutoff of July 
1 , by these additional policy changes. In other words, this setup allows me to separate the causal effect of start help from the immigration restrictions.

\section{Selection Biases and Causal Identification}

To isolate the causal effect of reducing the benefits of refugees on citizenship acquisition, one needs to compare two groups of refugees that are eligible for different levels of benefits but are otherwise similar on all other characteristics that can independently affect the naturalization process. Randomization would solve the fundamental problem of causal inference (Holland 1986) because it ensures that the two groups of refugees are similar on all measured and unmeasured characteristics. Randomizing benefits is, however, not possible. Instead, I focus on the Danish start help reform that provides a discontinuity in the social assistance levels of refugees: refugees who obtained Danish residency just before and after July 12002 were eligible for different benefits. I argue that this setting provides a natural experiment that I exploit in a $\mathrm{RD}$ design to overcome potential selection biases. The RD design provides unbiased estimates under the assumption that the potential naturalization outcomes are continuous at the cutoff of July 1 (Hanh, Todd, and Van der Klaauw 2001). This identifying assumption fails if refugees sort around the threshold, which would only happen if manipulation with the date of residency occurs. This manipulation could arise in two distinct stages.

In the first stage, refugees decide whether to apply for asylum in Denmark or not. If refugees were able to anticipate the reform, there is a risk that they sort in a manner that create selection bias in the effect estimates. However, the short parliamentary processing time of the reform combined with the mean asylum application processing time strongly suggest that first-stage selfselection is not a problem. Thus, the start help reform was proposed for the first time on March 1 2002 and in effect as of July 1 . At the same time, there was a mean asylum application processing 
time of about 15 months (Hvidtfeld et al. 2017). This implies that refugees did not have sufficient information to anticipate the reform when deciding in which country to apply for asylum.

In the second stage, applications are reviewed and it is decided who obtains a permit and who does not. Decision-makers that review applications typically decide on a much more informed basis about applicants than what the researcher observes. If decision-makers prefer specific refugees, it could create bias in the estimated effects. However, three factors alleviate the concern over second stage selection bias. First, it is not sufficient that decision-makers potentially prefer certain types of refugees to others to create bias in the estimates. They would also have to process their applications faster, which seems inconceivable. Second, the Danish Immigration Service - that decides whether there is a basis for granting asylum — bases its decision entirely on the legal criteria of the applicant's need for protection. Third, I control for a rich set of covariates. Although, this information does not match exactly the full information available to decision-makers it measures the important characteristics that is available in the registers.

Taken together, the above arguments provide strong substantive justification to believe that refugees are as-if randomly distributed across the start help cutoff. This corroborates the validity of the assumption of continuous potential outcomes under which the RD design provides a local experiment that - in the same way as a randomized experiment-enables me to isolate the causal effect of lower benefits and overcome the selection bias discussed above. However, it is important to recognize that the validity of the continuity assumption is ultimately an empirical question. I return to this question below.

\section{Data}

My data are based on the Danish national registers. I select all refugees - including those who are family reunified with refugees — who obtained their residency within a bandwidth of \pm 6 months from 
the start help cutoff. In the supplementary material (SM), I show that results are robust across various widths of the estimation window (see Figure A.1 in the SM). I focus only on refugees and their families because refugees and their reunified family members are the only immigrant group that are systematically affected by the reform (see the description of the start help above). I include only refugees between 18 and 55 years old, at the time of residency, who were eligible for social assistance. Moreover, I exclude refugees who at some point during the period of analysis re-migrate.

Based on this sample selection, I use the registers unique personal identifier to construct a dataset that links information on each refugee's exact date of residency to her citizenship status (the main outcome). The start help indicator (the treatment) is coded in accordance with the eligibility criteria (see the description of the start help above). The indicator takes the value 1 for refugees who obtained residency after cutoff of July 1, and 0 for refugees who obtained residency before. However, spouses that obtained residency on each side of July 1 are both assigned the value 1 on the treatment indicator as they are both de facto only eligible for start help. To ensure consistency between date of residency and eligibility status, these spouses are assigned the date of residency of the last arriving spouse.

I observe the main outcome, citizenship status, as of December 312015 . To account for the fact that refuges obtained residency at different points in time, the outcome is coded 100 if she acquired citizenship within the first 4380 days (i.e., 12 years) of her residency date and 0 if she remained non-citizen. This means that the outcome measures the percentage difference in naturalizations between the start help and regular assistance group. To test the mechanisms that links lower benefits and naturalization, I use employment and outmigration, respectively, as alternative outcomes. The employment indicator is a yearly measure that categorizes each refugee as employed (takes the value 100) if her main source of income over the preceding year derived from employment. That is, she was employed for at least half of the year. Instead, the measure categorizes refugees as 
not employed (takes the value 0 ) if they predominantly relied on welfare benefits or dropped out of the labor force altogether. I average this indicator over the first three full years of residency (i.e., 2003-2005). The outmigration indicator measures migration out of Denmark. The indicator takes the value 100 if a refugee migrates out of Denmark, and 0 if she stays.

I merge the treatment and outcome information with information about the refugee's background characteristics based on the personal identifier as well as unique spouse and family identifiers. These covariates capture background characteristics of the refugees as reported in the national registers. They include sex, age, education, grouped origin, first region of residency, whether the refugee is married or not, and whether the refugee has children or not. Table 2 provides an overview of the descriptive statistics for all variables described above for refugees within the bandwidth of \pm 6 months of the July 1 cutoff.

With this sample selection and data, the design allows me to estimate the causal effect of the start help policy on naturalization. This is akin to an intention-to-treat (ITT) estimate and not the average treatment effect (ATE) of actually receiving start help because refugees are only affected directly by the reform if they are unemployed. Three properties of this ITT effect are important to note. First, one might argue that the ITT is in fact the more relevant quantity to estimate from a policy perspective. Second, employment is indirectly a part of the outcome as self-sufficiency is a crucial requirement to become eligible for naturalization. In that sense, the ITT effect is capturing the incentives effect of reducing the welfare of refugees. Finally, given that refugees typically do not enter the job market immediately, most of them are in fact affected by the reform, at least during their first years in Denmark. 
Table 2. Descriptive Statistics for Refugees within the \pm 6 Months Bandwidth

\begin{tabular}{lcccc}
\hline \hline Variable & Mean & SD & Min & Max \\
\hline Start help indicator & 0.55 & 0.50 & 0.00 & 1.00 \\
Residency date (centered on the cutoff) & 12.77 & 111.27 & -181.00 & 182.00 \\
\hline Age & 32.61 & 8.00 & 18.00 & 54.92 \\
Female & 0.52 & 0.50 & 0.00 & 1.00 \\
Education (months) & 137.11 & 48.21 & 0.00 & 240.00 \\
Education levels & & & & \\
$\quad$ Level 1 & 0.17 & 0.38 & 0.00 & 1.00 \\
Level 2 & 0.16 & 0.36 & 0.00 & 1.00 \\
$\quad$ Level 3 & 0.38 & 0.49 & 0.00 & 1.00 \\
$\quad$ Level 4 & 0.20 & 0.40 & 0.00 & 1.00 \\
$\quad$ Level 5 & 0.09 & 0.29 & 0.00 & 1.00 \\
Married & 0.74 & 0.42 & 0.00 & 1.00 \\
Children & 0.74 & 0.44 & 0.00 & 1.00 \\
Grouped origin & & & & \\
East or Central Europe & 0.16 & 0.37 & 0.00 & 1.00 \\
Middle East & 0.68 & 0.48 & 0.00 & 1.00 \\
Africa & 0.15 & 0.36 & 0.00 & 1.00 \\
Americas & 0.001 & 0.03 & 0.00 & 1.00 \\
Stateless/unknown & 0.01 & 0.09 & 0.00 & 1.00 \\
Region of residency & & & & \\
Municipality & 0.16 & 0.37 & 0.00 & 1.00 \\
Zealand & 0.20 & 0.40 & 0.00 & 1.00 \\
Southern Jutland & 0.26 & 0.44 & 0.00 & 1.00 \\
Mid Jutland & 0.23 & 0.42 & 0.00 & 1.00 \\
Northern Jutland & 0.15 & 0.36 & 0.00 & 1.00 \\
Citizenship & 19.54 & 39.67 & 0.00 & 100.00 \\
Employment & 23.70 & 32.45 & 0.00 & 100.00 \\
Outmigration & 11.60 & 32.02 & 0.00 & 100.00 \\
\hline \hline
\end{tabular}

Note: All variables are measured in the Danish administrative registers. The top panel of the table presents the treatment data. The middle panel presents all individual background characteristics that are measured by the date of residency (i.e., the first entry in the registers). Education: level 1 corresponds to primary school; level 2 is more than primary school but less than high school, level 3 is a high school education; level 4 is equivalent to a bachelor's degree or higher; level 5 is missing data. The bottom panel presents the outcome measures. Citizenship is measured as of December 312015. Employment is averaged over the years 2003-2005. Outmigration indicates if the refugee migrated out of Denmark as of December 312015.

\section{Results}

Below, I estimate the effect of reducing the welfare of refugees on citizenship acquisition by regressing refugees' citizenship status on the start help indicator, the residency variable, and the interaction between the two. All effect estimations in the results section focus on the sample of refugees who obtained their residency within a bandwidth of \pm 6 months of the threshold. To probe 
the robustness of my results, I show that the results are relatively insensitive to varying the width of the estimation window (see Figure A.1 in the SM). Moreover, I demonstrate that the finding are robust to alternative specifications (see Table A.3 in the SM). In particular, I show that using a local quadratic specification instead of the local linear does not change the results. Furthermore, I also show that the results are essentially similar when estimating the effects within the CCT MSE-optimal bandwidth (Calonico, Cattaneo and Titiunik 2014). Finally, as I argue below, the identification checks indicate that the RD design is able to isolate this causal effect at the cutoff.

\section{Empirical Assessment of the Continuity Assumption}

Figure 1 illustrates two important indirect tests that check the identification of the RD design. One important corollary of the continuity assumption is that refugee characteristics should be smooth across the cutoff. It implies that covariates are balanced across cutoff. This logic builds on the intuition of a local experiment at the cutoff that allows for identification of causal effects in the same way as a randomized experiment. I utilize this logic in the left panel of Figure 1. In particular, I use each covariate in turn as placebo outcome in the RD design and estimate placebo effects for all covariates. From these analyses, I plot the respective p-values to show any imbalances across the cutoff(Table A.1 in the SM reports the supporting regression table). The dashed vertical line indicates a p-value of 0.05 . If selection in either the first or the second stage is a problem, one should expect to observe p-values below the 0.05 threshold.

Instead, the panel displays a distribution of p-values that is consistent with what one would expect to observe at random. That is, only 1 of 20 covariates is imbalanced across the cutoff: there are fewer females above the cutoff. The imbalance in sex reflects that men typically arrives first and are reunified with their spouses later. Given the treatment assignment, where both spouses would only be eligible for start help if one obtained residency above the cutoff, this means that men are 
disproportionately "moved" across the cutoff. ${ }^{4}$ To be sure, in the results section below, I provide estimates both with and without covariates.

Figure 1. The RD Design: Identification Checks

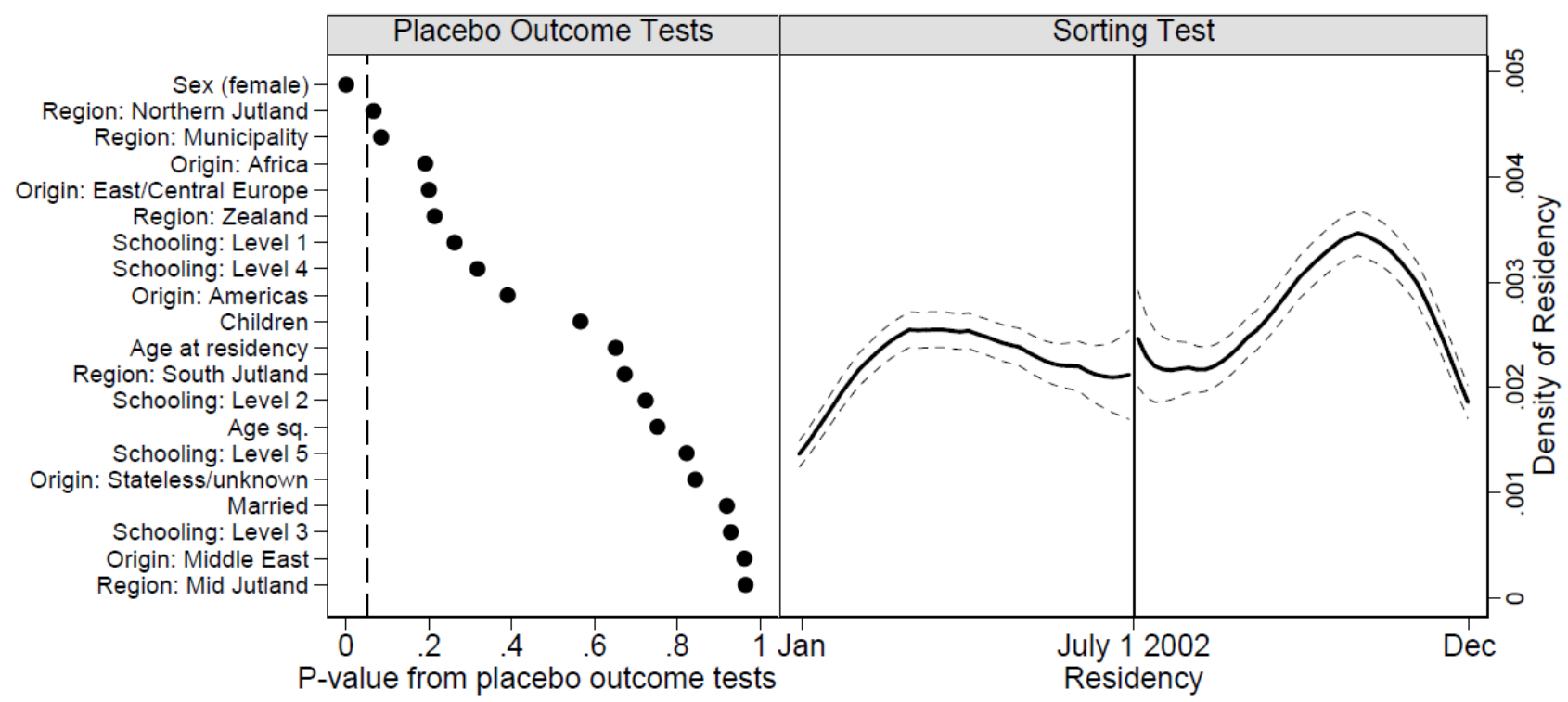

Note: The left panel shows that refugee background characteristics' well balanced across the threshold. The right panel shows that there is no discontinuity in the density of residency.

Another important implication of the continuity assumption is that the density of refugees should be smooth across the threshold. That is, there should be no sorting. If refugees had precise control over their date of residency and the ability to sort, one would logically expect to observe an unusually large (small) density of refugees who obtained residency just before (after) July 1. The right panel of Figure 1 shows McCrary's (2008) test for sorting. I compute the density of the residency variable (the difference in days between residency and the cutoff) within a window of \pm 6 months around the threshold. The panel shows that there was no sign of sorting. Instead, the density is smooth across the threshold.

\footnotetext{
${ }^{4}$ Thus, the imbalance disappears if one uses their own date of residency (disregarding family reunifications) as the running variable.
} 
Finally, Figure A.2 demonstrates that there are no discontinuities at placebo cutoffs above and below the true threshold. These tests further bolster the design-based identification and corroborate that the true effect estimate (see below) is indeed an effect of the start help reform rather than an artefact of a jumpy relationship between the forcing variable and the outcome.

\section{Overall Effect on Naturalization}

Figure 2 illustrates the main findings (Table A.2 in the SM reports the supporting regression table). The left panel displays graphically the results of applying the RD design, whereas the right panel displays the marginal difference in naturalization rates at the threshold from regression models with (filled grey triangle) and without (filled black circle) covariates, respectively. Refugees' propensity to naturalize jumps by about $13^{1 / 2}$ percentage points at the start help cutoff. Relative to the sample, this is a marked 70 percent increase in the naturalization rate. The inclusion of covariates checks the design-based identification. If refugees who obtain residency just before and after the threshold is similar in all confounding respects — as local randomization stipulates — then including or excluding covariates should not substantially alter the effect estimate. Consistent with the placebo outcome tests above, the effect is relatively stable across the models with and without covariates $\left(\alpha_{\mathrm{w} / \mathrm{o} \text { covariates }}=\right.$ $\left.13.55, P<0.002 ; \alpha_{\text {with covariates }}=9.99, P<0.012\right)$.

These results are striking as I compare refugees who are identical in terms of their background characteristics but separated by only a few days with regard to residency. Moreover, this sizable effect is robust across various robustness checks. Thus, Figure A.1 in the SM shows that the effect estimates are remarkably stable across different widths of the estimation window. Furthermore, Table A.3 in the SM demonstrates that the effect remains fundamentally unchanged when using alternative specifications, including the CCT optimal bandwidth (Calonico, Cattaneo and Titiunik 2014) and a local quadratic trend rather than the local linear. 
Figure 2. Overall Effect of Start Help on Propensity to Naturalize

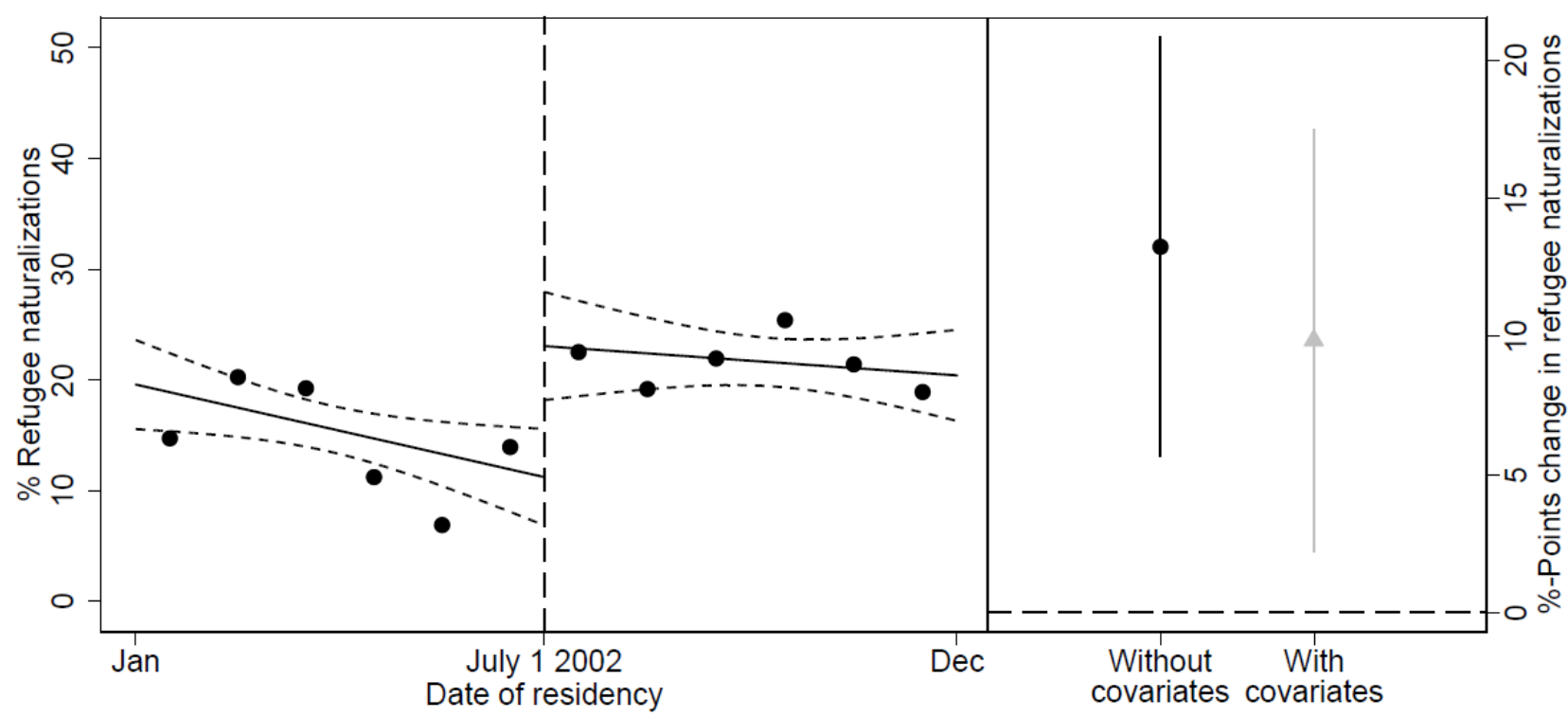

Note: The left panel displays the overall result on naturalization graphically from applying the RD. Lines are average naturalization rates (with 95\% confidence intervals). Right panel displays the regression results for models without (black circles) and with covariates (grey triangles), respectively (with 95\% confidence intervals). Standard errors are clustered by municipality. Bandwidth \pm 6 months. Covariates: Sex, age, education, married, children, grouped origin, and region of residency. $\mathrm{N}=2,324$.

Although these results are consistent with the hypothesis that lower benefits increase the benefits of becoming citizen and thereby provide an incentive for refugee to naturalize, they do not rule out the possibility that something other than incentives might be driving the effects. Theoretically, I argue that the start help reform clearly taps into the incentives mechanism by increasing the benefits of becoming citizen. To the contrary, I believe, that any signaling effect of the reform is broader in the sense that it affects refugees equally across the cutoff. This implies that the social context mechanism would be constant across the cutoff and that the difference in naturalization rates in fact reflects the incentives mechanism. It is important to recognize that separating between mechanisms is an empirical question. I try to get at this question below. 


\section{Testing the Mechanisms}

One way to get more directly at the mechanisms is to consider outcomes that are especially sensitive to the respective explanations. If lower benefits predominantly affect naturalization through increased incentives, then one should expect that the start help increases refugees' likelihood of employment in the short-term. Thus, short-term employment taps directly into the underlying incentives mechanism that reducing the assistance benefits for refugees provides an incentive to get off welfare and find employment as a stepping-stone toward integration into the host society more broadly. To test this proposition, I replicated the RD models using short-term employment as the outcome.

The left panel of Figure 3 graphically displays the results of applying the RD design with employment as the outcome whereas the right panel displays the marginal difference in employment rates at the threshold from regression models (Table A.4 in the SM reports the supporting regression table). Both panels demonstrate that there is a clear jump in the employment rate at the start help threshold. In particular, the employment rate jumps by about 10 to 15 percentage points as a consequence of the lower assistance benefits. Compared to the sample mean employment rate of about 24 percent, this is up to a marked 62 percent increase. Thus, the employment effect maps closely onto the naturalization effect, which strongly suggests that the incentives mechanism is driving the overall effect on naturalization.

Although the above results corroborate that incentives are an important driver of the overall effect estimates, it does not exclude that alternative mechanisms might also play a role. To rule out alternative mechanisms, I first trim the sample to include only refugees who found a job in the short-term. In this sample, I estimate the RD effect on naturalization. This test is designed to net out that part of the effects that are accounted for by the increase in incentives: the logic is that any remaining start help effect reflects alternative mechanisms. The left panel of Figure 4 shows that the start help effect on naturalization is essentially zero among refugees who found a job in the short- 
term (Table A.5 in the SM provides the supporting regression table). This provides important evidence that the effect of lower benefits on refugees' propensity to naturalize is driven by increased incentives rather than some alternative mechanism.

Figure 3. Incentives Mechanism: RD Effect on Short-Term Employment

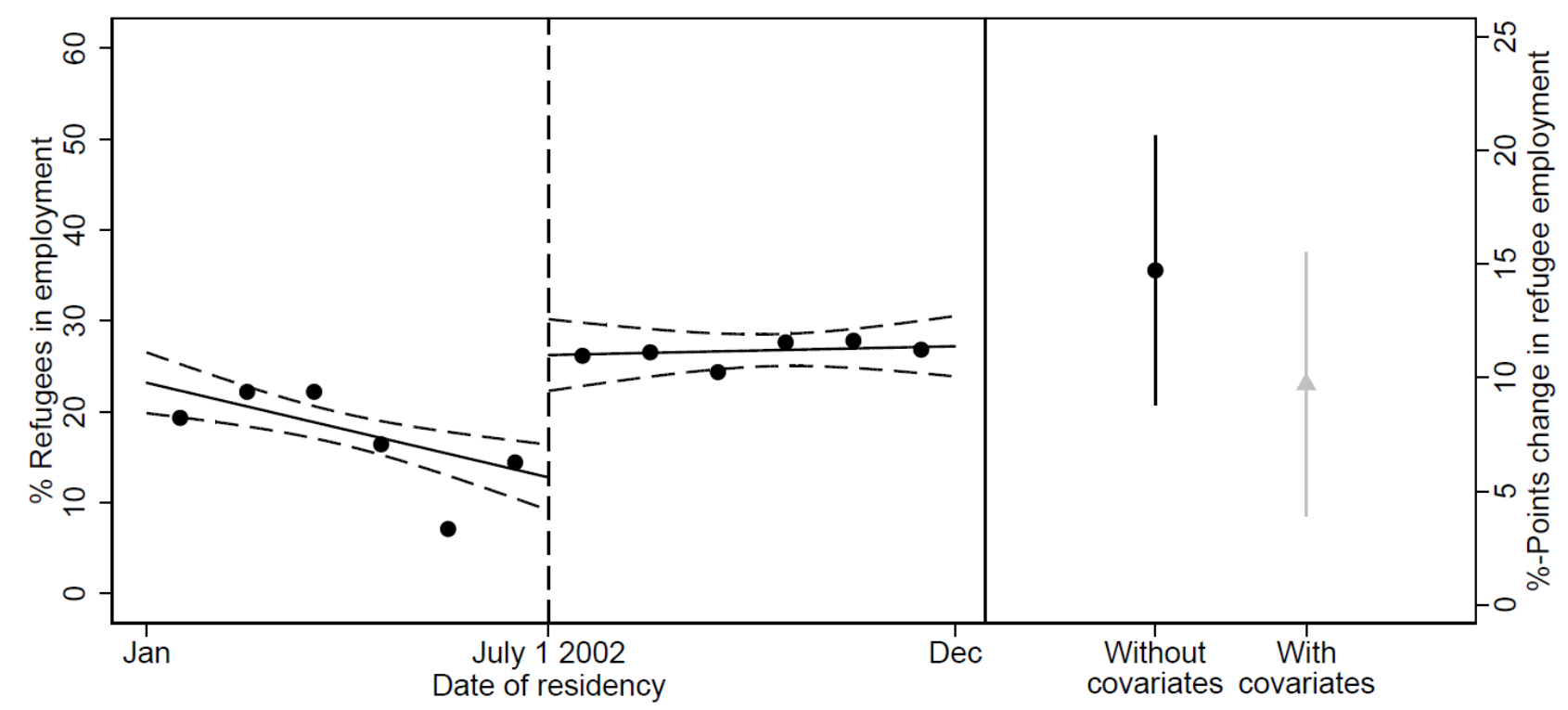

Note: The left panel displays the overall result on employment graphically from applying the RD. Lines are average naturalization rates (with 95\% confidence intervals). Right panel displays the regression results for models without (black circles) and with covariates (grey triangles), respectively (with 95\% confidence intervals). Standard errors are clustered by municipality. Bandwidth \pm 6 months. Covariates: Sex, age, education, married, children, grouped origin, and region of residency. $\mathrm{N}=2,324$.

Second, to get at the "context of reception" mechanism - as discussed in the theory section-I use migration out of Denmark as an alternative outcome and estimate the RD effects. Thus, outmigration can be expected to tap into the "context of reception" mechanism given that start help refugees should be more likely to migrate away from Denmark at higher rates if start help was perceived as a signal of discrimination only among the targeted refugees. The right panel of Figure 4 tests this conjecture and demonstrates that the estimated start help effect on outmigration is close to zero and statistically insignificant (Table A.5 in the SM provides the supporting regression table). 
This corroborates that the "context of reception" mechanism does not help to explain the overall findings. Taken together, the above findings provide strong evidence that the overall effect on naturalization reflects an underlying incentives mechanism.

Figure 4. Alternative Mechanisms

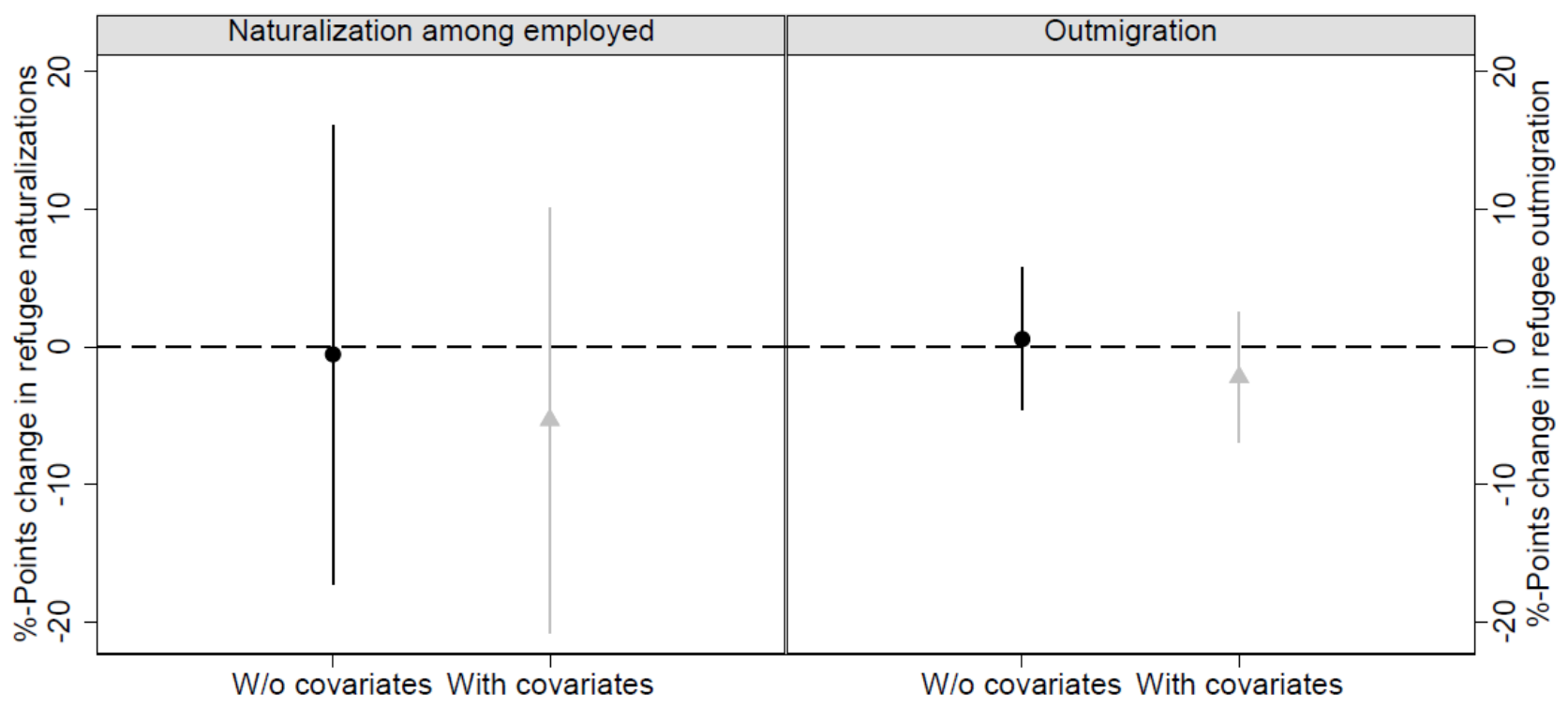

Note: The filled black circle represents the estimate from a model without covariates, whereas the grey filled triangle represents the estimate from a model with covariates. $95 \%$ confidence intervals. Standard errors are clustered by municipality. Bandwidth \pm 6 months. Covariates: Sex, age, education, married, children, grouped origin, and region of residency. $\mathrm{N}$ (employment sample $=685$; outmigration $=2,682$ ).

\section{Effect Heterogeneity}

As discussed in the theory section, it can be expected that the positive incentive effects are driven by the better educated who face fewer resource constraints and less marginalization. This implies an empirical pattern, where the high educated experience large start help effects on naturalization and employment, respectively, the medium educated experience lower effects, and the low educated experience small and insignificant effects. To test these predictions, I separately estimate the start help effects within education subgroups. In particular, I split education into low, medium and high 
educated. ${ }^{5}$ Figure 5 shows the results of these subgroup analyses for the RD models without covariates (Table A.6 in the SM reports the supporting regression table and also provides the results from models with covariates).

Figure 5. Are the Effects of Lower Benefits Heterogeneous?

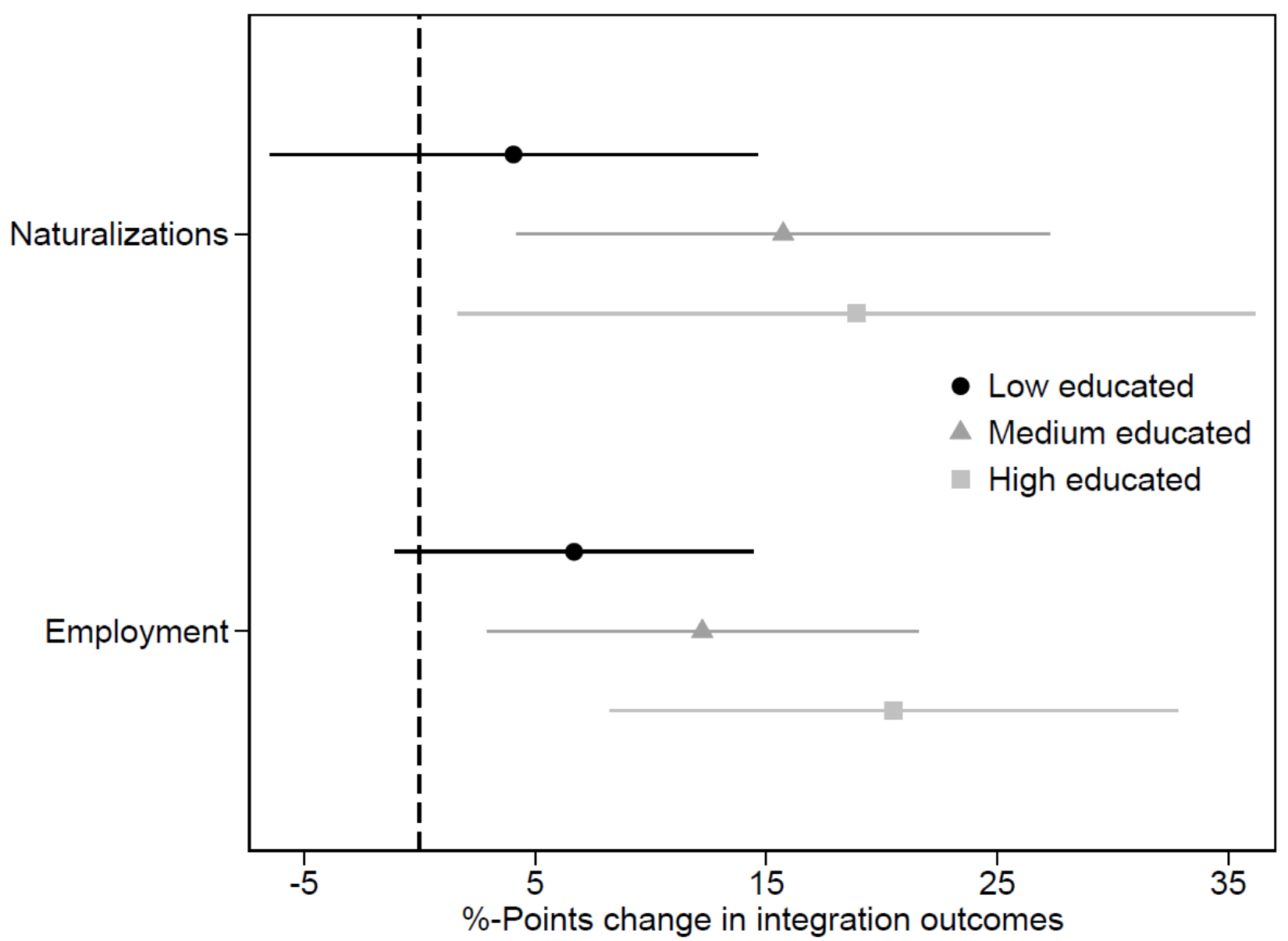

Note: the regression results for models without (black circles) and with covariates (grey triangles), respectively (with 95\% confidence intervals). Standard errors are clustered by municipality. Bandwidth \pm 6 months. Covariates: Sex, age, education, married, children, grouped origin, and region of residency. $\mathrm{N}($ low education $)=914 ; \mathrm{N}($ medium education $)=944 ; \mathrm{N}$ (high education $)=466$.

\footnotetext{
${ }^{5}$ I define low education as less than or equal to 120 months. This corresponds to $10^{\text {th }}$ grade in the Danish primary school. Moreover, to this group I also add refugees whose education level is unknown. Medium education is defined as more than 120 months, but less than 180 months that corresponds to a bachelor's degree. Finally, high education is more than 180 months.
} 
The empirical pattern in Figure 5 is consistent with the theoretical expectations. The largest effects are estimated among the high educated $\left(\alpha_{\text {citizenship acquisition }}=18.91, P<0.033 ; \alpha_{\text {employment }}\right.$ $=20.52, P<0.002)$, while they are somewhat smaller for the medium educated $\left(\alpha_{\text {citizenship acquisition }}=\right.$ $\left.15.74, P<0.009 ; \alpha_{\text {employment }}=12.24, P<0.011\right)$. Among the low educated, the effects are contrastingly relatively small and statistically insignificant $\left(\alpha_{\text {citizenship acquisition }}=4.07, P<0.450 ; \alpha_{\text {employment }}=6.69, P\right.$ $<0.091)$. Overall, it is clear from the subgroup analyses that the positive incentive effects are driven by the better educated. This gives a more nuanced picture of how lower benefits incentivize refugees: what the reductions in fact do is to push the better educated off welfare and into employment more quickly than they would have been had they instead been eligible for regular assistance. However, there is also a large group of low educated who experience little if any positive effects of lower benefits. For this group, the benefit reduction may instead pose a significant barrier for the integration into the host society.

\section{Conclusion}

In this study, I contribute to the ongoing debates about the link between integration policy and naturalization as a key measure of refugee integration. In particular, provide new and policy relevant causal evidence for the effect of reducing refugees' benefits on citizenship acquisition. I find that lower benefits have a strong effect on refugees' propensity to naturalize: reducing refugees' benefits increase their probability of naturalizing by about $13 \frac{1}{2}$ percentage points, which corresponds to an increase of about 70 percent relative to the sample mean. This result is striking as I compare refugees who are identical in terms of their background characteristics but separated by only a few days with regard to residency. Moreover, I demonstrate this overall effect most likely reflects an incentives mechanism, where the decrease in benefits should be understood as an increase in the benefits of becoming citizen. In particular, I show that the increased incentives of becoming citizen 
propel refugees to get off welfare and find employment as a stepping-stone to becoming citizen in the long-term. However, I also demonstrate how this mechanism seem to be driven by a certain subset of the refugees: the positive incentive effects are concentrated among the most capable refugees who do not face the resource constraints that follow from low education.

Theoretically, the findings align with recent work (e.g. Marbach et al. 2018, Hainmueller et al. 2016) that points to the existence of an influential early integration window that affect refugees' subsequent integration trajectory disproportionately. From a policy standpoint, this is concerning because it suggests that low benefits marginalize those who have little chances of integrating into the host society at the outset and push them further to the edges of the society. Thus, while the large benefit reduction incentivizes the most resourceful to naturalize, this positive effect is absent among least resourceful. For this group of refugees, the large benefit reduction might instead pose a substantial barrier to their integration into the host society because they are placed on a subsistence minimum. In a companion study, I show how the reduction in benefits negatively influences this group's long-term residential integration: they live more ethnically segregated in the long-term compared to regular assistance refugees.

Finally, the juxtaposition of my results and the findings of Hainmueller et al. (2018), reveals important implications for our understanding of how incentives influence refugees' likelihood of naturalizing. My results show that increasing the benefits of becoming citizen (or increasing the costs of remaining non-citizen) influences those refugees who are most resourceful and face the smallest resource constraints. In comparison, the results of Hainmueller et al. (2018) show that alleviating the costs of becoming citizen have the largest effects among the less resourceful who face the largest resource constraints. For theory, this suggests that incentives do exert a symmetrical influence: benefit-targeting policies might be especially powerful to incentivize the most resourceful, while cost-targeting policies might be a better tool among the less resourceful. For policy, this implies 
that governments should consider designing policies that target the costs rather than the benefits of becoming citizen. 


\section{References}

Abbring, J. H., Van den Berg, G. J., \& Van Ours, J. C. 2005. "The effect of unemployment insurance sanctions on the transition rate from unemployment to employment." The Economic Journal, 115(505), 602-630.

Aleinikoff, T Alexander. 2001. "Policing Boundaries: Migration, Citizenship, and the State." E pluribus unum? Contemporary and historical perspectives on immigrant political incorporation:267-91.

Aleinikoff, T Alexander and Douglas Klusmeyer. 2011. Citizenship Policies for an Age of Migration: Carnegie Endowment.

Bauböck, Rainer, Eva Ersbøll, Kees Groenendijk and Harald Waldrauch. 2006. Acquisition and Loss of Nationality: Policies and Trends in 15 European States, Vol. 2: Amsterdam University Press Amsterdam.

Bauböck, Rainer, Iseult Honohan, Thomas Huddleston, Derek Hucheson, Jo Shaw and Maarten Peter Vink. 2013. "Access to Citizenship and Its Impact on Immigrant Integration: European Summary and Standards."

Bevelander, Pieter and Don J DeVoretz. 2008. The Economics of Citizenship: Malmö University (MIM).

Bloemraad, Irene. 2006. "Citizenship Lessons from the Past: The Contours of Immigrant Naturalization in the Early 20th Century." Social Science Quarterly 87(5):927-53.

Bratsberg, Bernt, Jr Ragan, James F and Zafar M Nasir. 2002. "The Effect of Naturalization on Wage Growth: A Panel Study of Young Male Immigrants." Journal of labor economics 20(3):56897.

Borjas, George J. 1998. "To ghetto or not to ghetto: Ethnicity and residential segregation." Journal of Urban Economics 44 (2):228-253.

Bover, O., Arellano, M., \& Bentolila, S. 2002. "Unemployment duration, benefit duration and the business cycle." The Economic Journal, 112(479), 223-265.

Calonico, S., Cattaneo, M. D., \& Titiunik, R. (2014). Robust nonparametric confidence intervals for regression-discontinuity designs. Econometrica, 82(6), 2295-2326.

Carr, Jillian, and Analisa Packham. (2017). "SNAP Benfits and Crime: Evidence from Changing Disbursement Schedules". Miami University, Department of Economics Working Paper \#2017-01.

Corman, Hope, Dhaval M. Dave, and Nancy E. Reichman. (2014). "Effects of welfare reform on women's crime," International Review of Law and Economics 40(C): 1-14.

Crowder, Kyle, and Maria Krysan. 2016. "Moving Beyond the Big Three: A Call for New Approaches to Studying Racial Residential Segregation." City \& Community 15 (1):18-22.

Dahl, Gordon B, and Lance Lochner. (2012)."The Impact of Family Income on Child Achievement:Evidence from the Earned Income Tax Credit". American Economic Review 102(5): 1927-956.

Danish Prime Minister's Office. 2002. "På Vej Mod En Ny Integrationspolitik." Vol. Copenhagen: Danish Prime Minister's Office.

Duncan, Greg J., Pamela A. Morris, and Chris Rodrigues. (2011). "Does Money Really Matter? Estimating Impacts of Family Income on Young Children's Achievement with Data from Random-Assignment Experiments". Developmental Psychology 47(5): 1263-1279.

Ejrnæs, M. (2003). Starthjcelp: Andenrangsborgere fra begyndelsen: Når du strammer garnet - et opgør med mobning af mindretal og ansvarsløs asylpolitik. Aarhus: Aarhus Universitetsforlag. 
Ersbøll, Eva. 2015. Report on Citizenship Law: Denmark. European University Institute, Florence, Robert Schuman Centre for Advanced Studies, EUDO Citizenship Observatory.

Foley, D. Fritz. (2011). "Welfare Payments and Crime". The Review of Economics and Statistics 93(1): 97-112.

Fox, Cybelle, \& Bloemraad, Irene. 2015. Beyond "white by law": Explaining the gulf in citizenship acquisition between Mexican and European immigrants, 1930. Social Forces 94(1), 181-207.

Hahn, Jinyong, Petra Todd and Wilbert Van der Klaauw. 2001. "Identification and Estimation of Treatment Effects with a Regression-Discontinuity Design." Econometrica 69(1):201-09.

Hainmueller, J., \& Hangartner, D. (2013). Who gets a Swiss passport? A natural experiment in immigrant discrimination. American Political Science Review, 107(1), 159-187.

Hainmueller, Jens, Dominik Hangartner and Giuseppe Pietrantuono. 2015. "Naturalization Fosters the Long-Term Political Integration of Immigrants." Proceedings of the National Academy of Sciences 112(41):12651-56.

Hainmueller, Jens, Dominik Hangartner and Duncan Lawrence. 2016. When lives are put on hold: Lengthy asylum processes decrease employment among refugees. Science advances, 2(8), e1600432.

Hainmueller, Jens, Dominik Hangartner and Giuseppe Pietrantuono. 2017. "Catalyst or Crown: Does Naturalization Promote the Long-Term Social Integration of Immigrants?". American Political Science Review, 111(2), 256-276.

Hainmueller, Jens, Duncan Lawrence, Justin Gest, Michael Hotard, Rey Koslowski and David D Laitin. 2018. "A Randomized Controlled Design Reveals Barriers to Citizenship for LowIncome Immigrants." Proceedings of the National Academy of Sciences: 201714254.

Hainmueller, J., Hangartner, D., \& Ward, G. (2019). Acquisition of Citizenship Increases the LongTerm Earnings of Marginalizaed Immigratns, Working Paper.

Harder, N., Figueroa, L., Gillum, R. M., Hangartner, D., Laitin, D. D., \& Hainmueller, J. 2018. Multidimensional measure of immigrant integration. Proceedings of the National Academy of Sciences, 115(45), 11483-11488.

Holland, Paul W. 1986. "Statistics and Causal Inference." Journal of the American statistical Association 81(396):945-60.

Huynh, Duy T, Marie Louise Schultz-Nielsen and Torben Tranæs. 2007. Employment Effects of Reducing Welfare to Refugees: Rockwool Foundation.

Hvidtfeldt, Camilla, Marie L. Schultz-Nielsen, Erdal Tekin and Mogens Fosgerau. 2017. "Asylum Process and Employment among Refugees: How Bad is Waiting Time?" Working paper.

Joppke, Christian. 2010. Citizenship and Immigration, Vol. 2: Polity.

Løken, Katrine V., Magne Mogstad, and Matthew Wiswall. 2012. "What Linear Estimators Miss: The Effects of Family Income on Child Outcomes". American Economic Journal: Applied Economics 4(2): 1-3.

Marbach, Moritz, Jens Hainmueller and Dominik Hangartner. (2018). The long-term impact of employment bans on the economic integration of refugees. Science advances, 4(9), eaap9519.

Mortensen, Dale T. 1977. “Unemployment insurance and job search decisions.” ILR Review, 30(4), 505-517.

Mossaad, N., Ferwerda, J., Lawrence, D., Weinstein, J. M., \& Hainmueller, J. (2018). Determinants of refugee naturalization in the United States. Proceedings of the National Academy of Sciences, 115(37), 9175-9180.

Portes, Alejandro and Rubén G Rumbaut. 2001. Legacies: The Story of the Immigrant Second Generation: Univ of California Press. 
Reitz, Jeffrey G. 2003. Host Societies and the Reception of Immigrants: Center for Comparative Immigration Studies, University of California, San Diego La Jolla, CA.

Rosholm, Michael and Rune Vejlin. 2010. "Reducing Income Transfers to Refugee Immigrants: Does Start-Help Help You Start?". Labour Economics 17(1):258-75.

Sager, Lutz. 2012. "Residential segregation and socioeconomic neighbourhood sorting: Evidence at the micro-neighbourhood level for migrant groups in Germany." Urban Studies 49 (12):26172632.

Steinhardt, Max Friedrich. 2012. "Does Citizenship Matter? The Economic Impact of Naturalizations in Germany." Labour Economics 19(6):813-23.

Van Hook, Jennifer, Susan K Brown and Frank D Bean. 2006. "For Love or Money? Welfare Reform and Immigrant Naturalization." Social forces 85(2):643-66.

Van Ours, J. C., \& Vodopivec, M. 2004. "How changes in benefits entitlement affect job-finding: Lessons from the Slovenian experiment."

Van Ours, J. C., \& Vodopivec, M. 2006. "Shortening the potential duration of unemployment benefits does not affect the quality of post-unemployment jobs: evidence from a natural experiment."

Vink, Maarten Peter, Tijana Prokic-Breuer and Jaap Dronkers. 2013. "Immigrant Naturalization in the Context of Institutional Diversity: Policy Matters, but to Whom?". International Migration 51(5):1-20.

Yang, Philip Q. 1994. "Explaining Immigrant Naturalization." International Migration Review:44977. 


\section{SUPPLEMENTARY MATERIAL (not for publication)}

\section{Robustness Test for Different Bandwidths}

Figure A.1. Sensitivity over Bandwidths

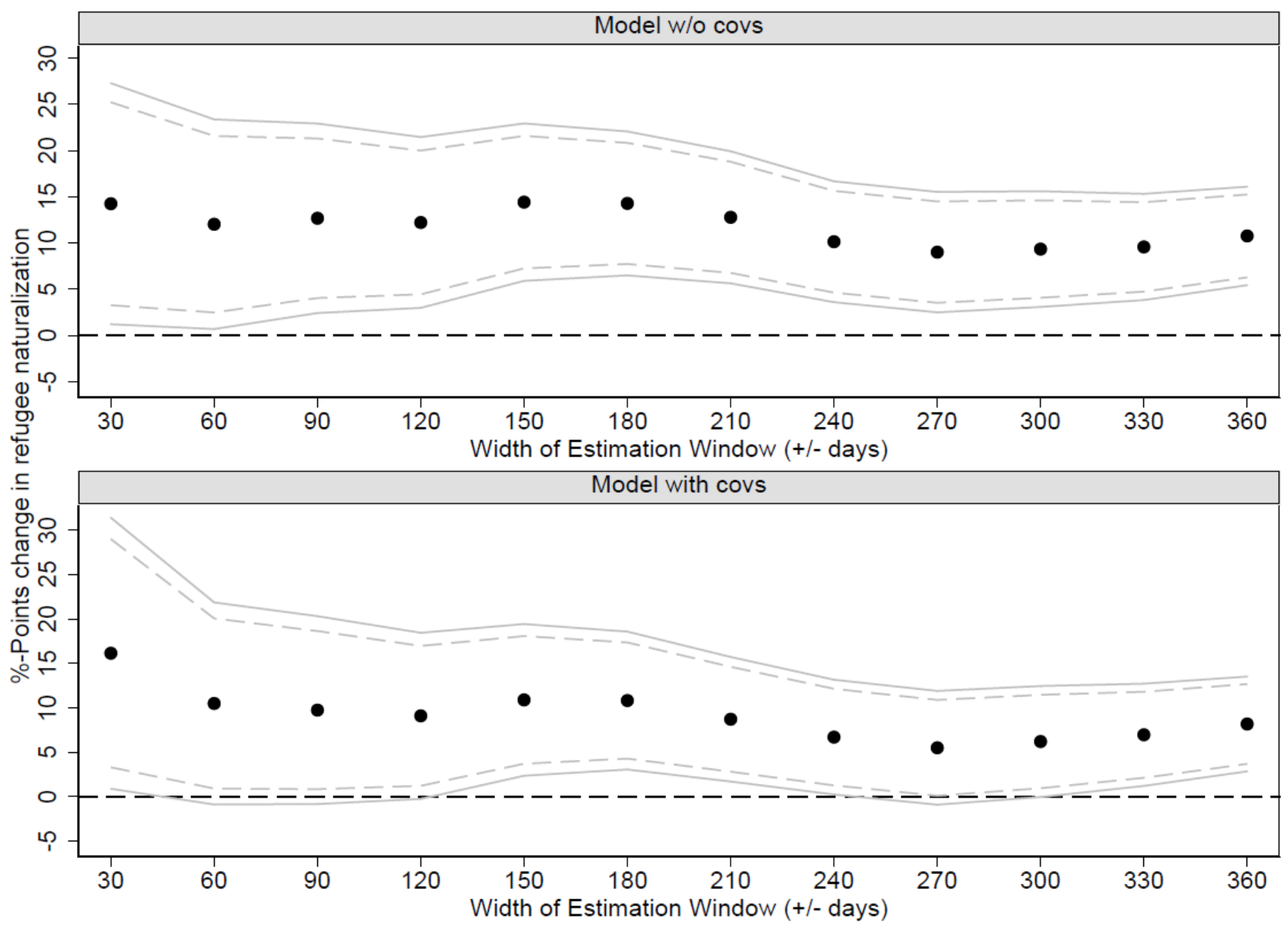

Note: The figure shows the estimated effect of start help on the propensity to naturalize and timing, respectively, as a function of the bandwidth. Dots represent the point estimates based on the sample within the corresponding value of the forcing variable. The grey solid and dashed lines show the $90 \%$ and $95 \%$ confidence intervals, respectively. 
Figure A.2. Overall Effects of Start Help on Propensity to Naturalize at Placebo Thresholds

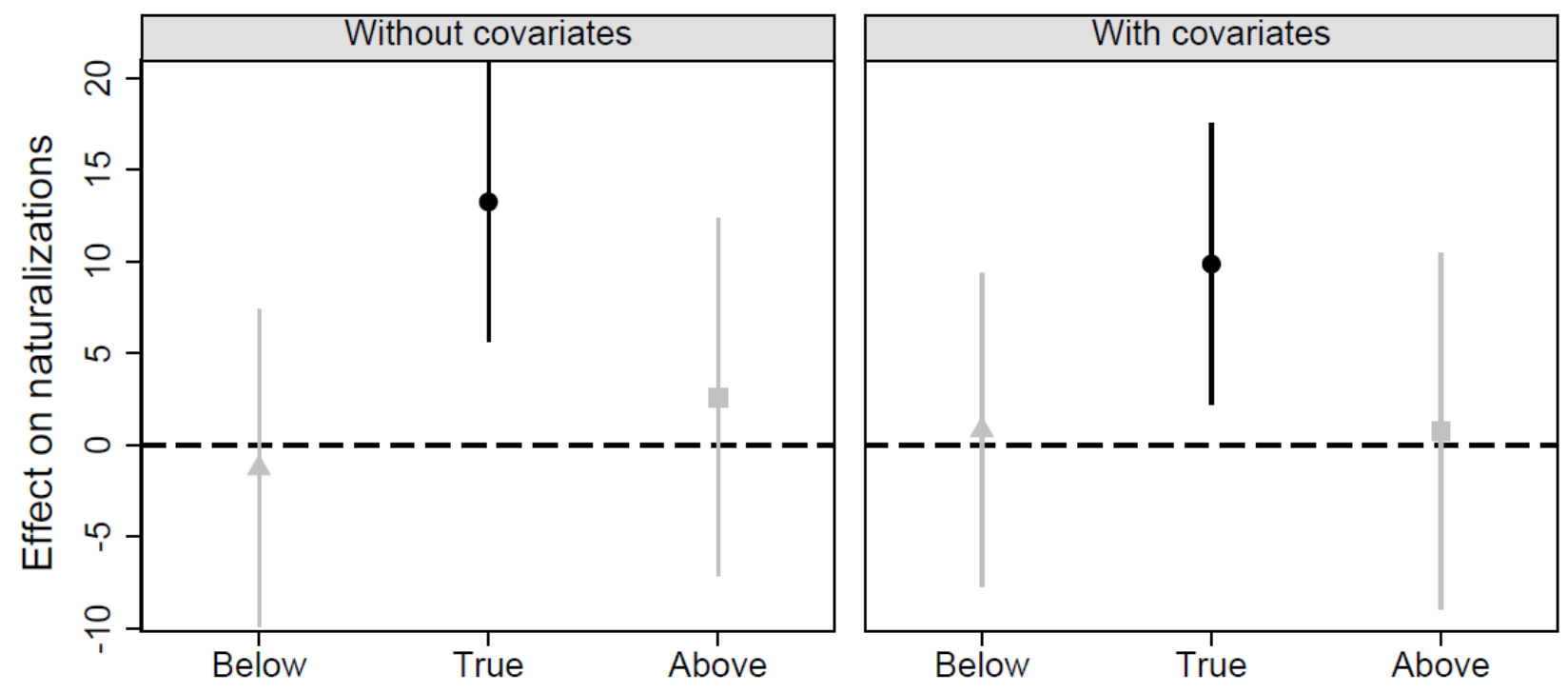

Note: Placebo effect estimates from the RD design. The grey filled triangles and squares show the estimated placebo treatment effect at the (placebo) threshold below and above the true threshold, respectively. The filled black circles show the effect estimate at the true threshold. Standard errors are clustered by municipality. $95 \%$ confidence intervals. The placebo estimate below the threshold uses only observations below the threshold, and the placebo threshold is set at the median. The placebo estimate above the threshold uses only observations above the threshold, and the placebo threshold is set at the median. The figure demonstrates that the observed jump in naturalization, at the true threshold, indeed seems to be an effect of the start help reform and not an artefact of a jumpy relationship between the forcing variable and the outcome. Overall, this corroborates the key identifying assumption of local random assignment at threshold. 
Table A.1. RD Placebo Effect Estimates

\begin{tabular}{|c|c|c|c|c|c|c|c|c|c|c|}
\hline Model & $(1)$ & $(2)$ & $(3)$ & $(4)$ & $(5)$ & $(6)$ & $(7)$ & $(8)$ & $(9)$ & $(10)$ \\
\hline Placebo outcome & Age & Age sq. & Female & Married & Children & Africa & $\begin{array}{l}\text { Middle } \\
\text { East }\end{array}$ & $\begin{array}{c}\text { East/Central } \\
\text { Europe }\end{array}$ & Americas & $\begin{array}{l}\text { Stateless/ } \\
\text { unknown }\end{array}$ \\
\hline Treatment effect & $\begin{array}{c}0.38 \\
(0.83) \\
\end{array}$ & $\begin{array}{c}18.50 \\
(58.63) \\
\end{array}$ & $\begin{array}{c}-0.28 * * * \\
(0.04)\end{array}$ & $\begin{array}{l}-0.01 \\
(0.05) \\
\end{array}$ & $\begin{array}{l}-0.03 \\
(0.05) \\
\end{array}$ & $\begin{array}{c}0.07 \\
(0.06) \\
\end{array}$ & $\begin{array}{l}-0.00 \\
(0.07) \\
\end{array}$ & $\begin{array}{c}-0.08 \\
(0.06) \\
\end{array}$ & $\begin{array}{c}0.00 \\
(0.00) \\
\end{array}$ & $\begin{array}{c}0.00 \\
(0.02) \\
\end{array}$ \\
\hline Residency date & $\begin{array}{l}-0.00 \\
(0.01)\end{array}$ & $\begin{array}{c}-0.32 \\
(0.41)\end{array}$ & $\begin{array}{c}0.00 * * * \\
(0.00)\end{array}$ & $\begin{array}{l}0.00 \\
(0.00)\end{array}$ & $\begin{array}{c}0.00 \\
(0.00)\end{array}$ & $\begin{array}{c}0.00 * * * \\
(0.00)\end{array}$ & $\begin{array}{c}-0.00 * * \\
(0.00)\end{array}$ & $\begin{array}{c}0.00 \\
(0.00)\end{array}$ & $\begin{array}{c}0.00 \\
(0.00)\end{array}$ & $\begin{array}{c}0.00 \\
(0.00)\end{array}$ \\
\hline $\begin{array}{l}\text { Treatment } x \\
\text { Residency date }\end{array}$ & $\begin{array}{c}0.01 \\
(0.01) \\
\end{array}$ & $\begin{array}{c}0.88 \\
(0.54) \\
\end{array}$ & $\begin{array}{c}-0.00 * * * \\
(0.00)\end{array}$ & $\begin{array}{l}-0.00 \\
(0.00)\end{array}$ & $\begin{array}{l}-0.00 \\
(0.00) \\
\end{array}$ & $\begin{array}{c}-0.00 * * * \\
(0.00)\end{array}$ & $\begin{array}{c}0.00 * * * \\
(0.00)\end{array}$ & $\begin{array}{l}-0.00 \\
(0.00)\end{array}$ & $\begin{array}{l}-0.00 \\
(0.00) \\
\end{array}$ & $\begin{array}{l}-0.00 \\
(0.00)\end{array}$ \\
\hline Model & $(11)$ & $(12)$ & $(13)$ & $(14)$ & $(15)$ & $(16)$ & $(17)$ & $(18)$ & (19) & $(20)$ \\
\hline Placebo outcome & $\begin{array}{l}\text { Schooling: } \\
\text { Level } 1\end{array}$ & $\begin{array}{l}\text { Schooling: } \\
\text { Level } 2\end{array}$ & $\begin{array}{l}\text { Schooling: } \\
\text { Level } 3\end{array}$ & $\begin{array}{l}\text { Schooling: } \\
\text { Level } 4\end{array}$ & $\begin{array}{l}\text { Schooling: } \\
\text { Level } 5\end{array}$ & $\begin{array}{c}\text { Region: } \\
\text { Municipality }\end{array}$ & $\begin{array}{l}\text { Region: } \\
\text { Zealand }\end{array}$ & $\begin{array}{l}\text { Region: } \\
\text { South } \\
\text { Jutland }\end{array}$ & $\begin{array}{l}\text { Region: } \\
\text { Mid } \\
\text { Jutland }\end{array}$ & $\begin{array}{l}\text { Region: } \\
\text { Northern } \\
\text { Jutland }\end{array}$ \\
\hline Treatment effect & $\begin{array}{l}-0.05 \\
(0.04) \\
\end{array}$ & $\begin{array}{c}0.01 \\
(0.04) \\
\end{array}$ & $\begin{array}{l}-0.00 \\
(0.05)\end{array}$ & $\begin{array}{c}0.04 \\
(0.04) \\
\end{array}$ & $\begin{array}{l}-0.01 \\
(0.04)\end{array}$ & $\begin{array}{c}0.09 \\
(0.05) \\
\end{array}$ & $\begin{array}{c}0.06 \\
(0.05) \\
\end{array}$ & $\begin{array}{l}-0.03 \\
(0.06)\end{array}$ & $\begin{array}{l}-0.00 \\
(0.07)\end{array}$ & $\begin{array}{l}-0.11 \\
(0.06)\end{array}$ \\
\hline Residency date & $\begin{array}{c}0.00 \\
(0.00)\end{array}$ & $\begin{array}{l}-0.00 \\
(0.00)\end{array}$ & $\begin{array}{l}-0.00 \\
(0.00)\end{array}$ & $\begin{array}{l}-0.00 \\
(0.00)\end{array}$ & $\begin{array}{l}-0.00 \\
(0.00)\end{array}$ & $\begin{array}{l}-0.00^{*} \\
(0.00)\end{array}$ & $\begin{array}{l}-0.00 \\
(0.00)\end{array}$ & $\begin{array}{c}0.00 \\
(0.00)\end{array}$ & $\begin{array}{c}0.00 \\
(0.00)\end{array}$ & $\begin{array}{c}0.00 \\
(0.00)\end{array}$ \\
\hline $\begin{array}{l}\text { Treatment } x \\
\text { Residency date }\end{array}$ & $\begin{array}{l}-0.00 \\
(0.00)\end{array}$ & $\begin{array}{c}0.00 \\
(0.00) \\
\end{array}$ & $\begin{array}{c}0.00 \\
(0.00)\end{array}$ & $\begin{array}{l}-0.00 \\
(0.00)\end{array}$ & $\begin{array}{c}0.00 \\
(0.00)\end{array}$ & $\begin{array}{c}0.00 \\
(0.00)\end{array}$ & $\begin{array}{c}0.00 \\
(0.00) \\
\end{array}$ & $\begin{array}{l}-0.00 \\
(0.00)\end{array}$ & $\begin{array}{l}-0.00 \\
(0.00)\end{array}$ & $\begin{array}{l}-0.00 \\
(0.00)\end{array}$ \\
\hline Observations & 2,324 & 2,324 & 2,324 & 2,324 & 2,324 & 2,324 & 2,324 & 2,324 & 2,324 & 2,324 \\
\hline
\end{tabular}

Note: Regression coefficients from local linear regression; standard errors clustered by first municipality in parentheses. $* P<0.05, * * P<$ $0.01, * * * P<0.001$. 
Table A.2. Overall Effect of Start Help on Propensity to Naturalize

\begin{tabular}{lcc}
\hline \hline Model & $(1)$ & $(2)$ \\
\hline Treatment effect & $13.55^{* * *}$ & $9.99^{* *}$ \\
& $(3.88)$ & $(3.89)$ \\
\hline Residency date & $-0.05^{*}$ & -0.03 \\
& $(0.02)$ & $(0.02)$ \\
Treatment $x$ Residency date & 0.03 & -0.01 \\
& $(0.03)$ & $(0.03)$ \\
\hline Covariates & $\mathrm{x}$ & $\checkmark$ \\
\hline Observations & 2,324 & 2,324 \\
\hline \hline
\end{tabular}

Note: Regression coefficients from local linear regression; standard errors clustered by first municipality in parentheses. ${ }^{*} P<0.10,{ }^{*} P<0.05,{ }^{* * *} P<0.01$. The outcome is coded as 0 or 100 such that the effect estimates are measured in percentage points.

Table A.3. Overall RD effect for alternative specifications

\begin{tabular}{lcc}
\hline \hline Model & CCT optimal & Local quadratic \\
\hline Treatment Effect & $11.46^{* * *}$ & $13.73^{* *}$ \\
& $(3.57)$ & $(5.36)$ \\
\hline Bandwidth & \pm 282 (days) & \pm 6 months \\
\hline Observations & 4,088 & 2,324 \\
\hline \hline
\end{tabular}

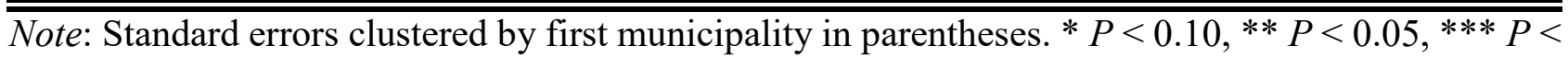
0.01 . The outcome is coded as 0 or 100 such that the effect estimates are measured in percentage points. Kernel $=$ uniform. 
Table A.4. Incentives Mechanism: RD Effect on Short-Term Employment

\begin{tabular}{lcc}
\hline \hline Model & $(1)$ & $(2)$ \\
\hline Treatment effect & $14.72^{* * *}$ & $9.70^{* * *}$ \\
& $(3.00)$ & $(2.95)$ \\
\hline Residency date & $-0.06^{* * *}$ & -0.02 \\
& $(0.02)$ & $(0.02)$ \\
Treatment $x$ Residency date & $0.06^{* *}$ & 0.02 \\
& $(0.03)$ & $(0.03)$ \\
\hline Covariates & $x$ & $\checkmark$ \\
\hline Observations & 2,324 & 2,324 \\
\hline \hline
\end{tabular}

Note: Regression coefficients from local linear regression; standard errors clustered by first municipality in parentheses. ${ }^{*} P<0.10, * * P<0.05$, *** $P<0.01$. The outcome is coded as 0 or 100 such that the effect estimates are measured in percentage points.

Table A.5. Alternative Mechanisms

\begin{tabular}{lcccc}
\hline \hline Model & $(1)$ & $(2)$ & $(3)$ & $(4)$ \\
\hline Outcome & Naturalization & Naturalization & Outmigration & Outmigration \\
\hline Treatment effect & -0.55 & -5.32 & 0.56 & -2.21 \\
& $(8.46)$ & $(7.83)$ & $(2.63)$ & $(2.42)$ \\
\hline Residency date & -0.02 & -0.01 & 0.03 & 0.01 \\
& $(0.06)$ & $(0.06)$ & $(0.02)$ & $(0.02)$ \\
Treatment $x$ & 0.01 & 0.01 & $-0.08^{* * *}$ & -0.02 \\
Residency date & $(0.07)$ & $(0.07)$ & $(0.03)$ & $(0.03)$ \\
\hline Covariates & $\mathrm{x}$ & $\checkmark$ & $\mathrm{X}$ & $\checkmark$ \\
\hline Observations & 685 & 685 & 2,682 & 2,682 \\
\hline \hline
\end{tabular}

Note: Regression coefficients from local linear regression; standard errors clustered by first municipality in parentheses. ${ }^{*} P<0.10, * * P<0.05$, *** $P<0.01$. The outcomes are coded as 0 or 100 such that the effect estimates are measured in percentage points. 
Table A.6. Effect Heterogeneity

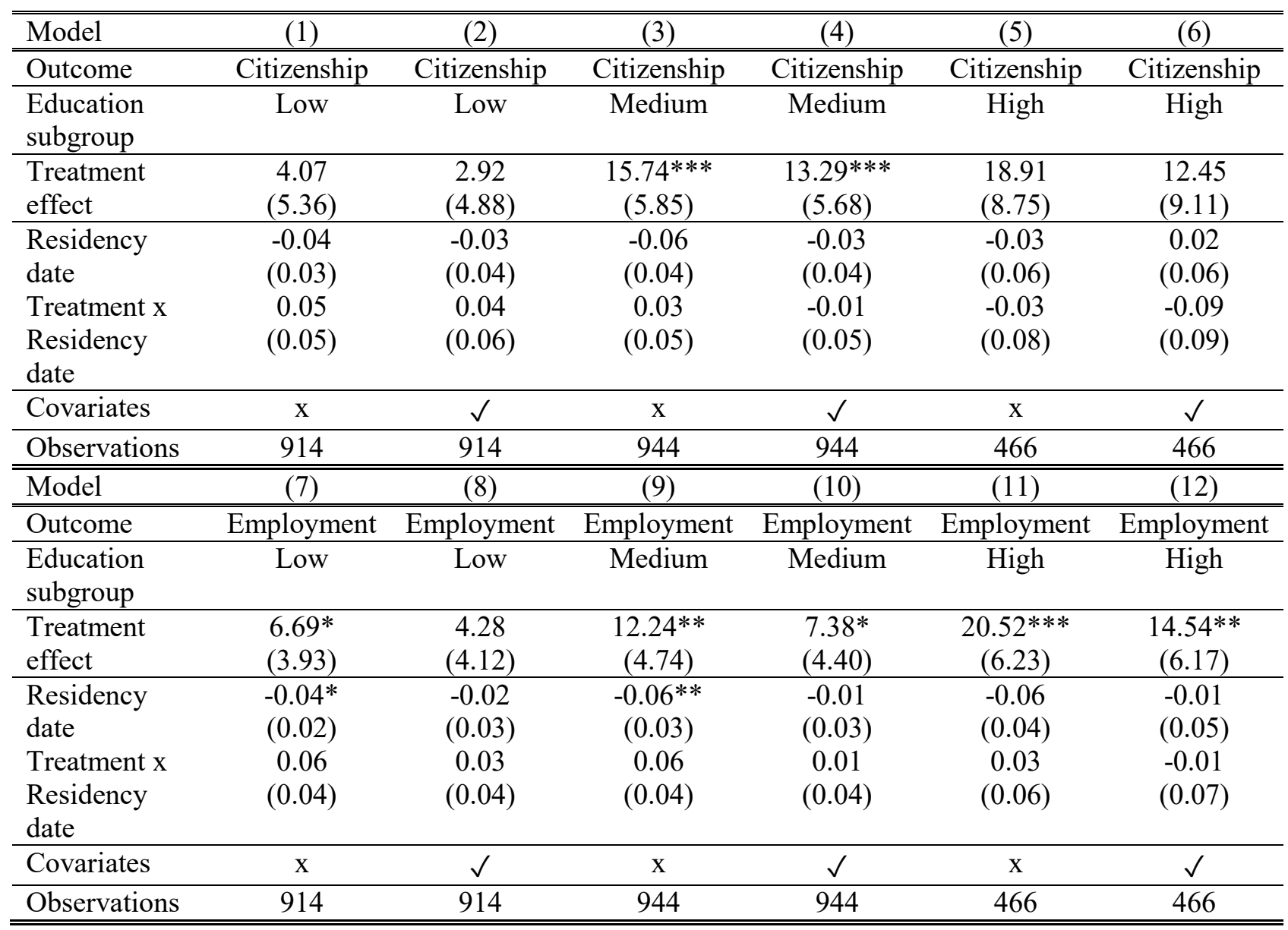

Note: Regression coefficients from local linear regression; standard errors clustered by first municipality in parentheses. $* P<0.10, * * P<0.05$, *** $P<0.01$. The outcome is coded as 0 or 100 such that the effect estimates are measured in percentage points. 